Erratum

\title{
Erratum to “A Novel Method for Extraction of Galegine by Molecularly Imprinted Polymer (MIP) Technique Reinforced with Graphene Oxide and Its Evaluation Using Polarography"
}

\author{
M. Azimi, M. Ahmadi Golsefidi (D), A. Varasteh Moradi, M. Ebadi, and R. Zafar Mehrabian \\ Department of Chemistry, Faculty of Sciences, Gorgan Branch, Islamic Azad University, Gorgan, Iran \\ Correspondence should be addressed to M. Ahmadi Golsefidi; mahmadig@gmail.com
}

Received 5 December 2020; Accepted 5 December 2020; Published 13 February 2021

Copyright (c) $2021 \mathrm{M}$. Azimi et al. This is an open access article distributed under the Creative Commons Attribution License, which permits unrestricted use, distribution, and reproduction in any medium, provided the original work is properly cited.

In the article titled "A Novel Method for Extraction of Galegine by Molecularly Imprinted Polymer (MIP) Technique Reinforced with Graphene Oxide and Its Evaluation Using Polarography" [1], there was a spell error in author M. Ebadii's name in the author list, where "M. Ebadii" should have read as "M. Ebadi." This is corrected as shown above.

The error was introduced during the production process of the article, and Hindawi apologises for causing this error in the article.

\section{References}

[1] M. Azimi, M. Ahmadi Golsefidi, A. Varasteh Moradi, M. Ebadii, and R. Zafar Mehrabian, "A novel method for extraction of galegine by molecularly imprinted polymer (MIP) technique reinforced with graphene oxide and its evaluation using polarography," Journal of Analytical Methods in Chemistry, vol. 2020, Article ID 3646712, 9 pages, 2020. 